J Arid Land (2014) 6(3): 243-254

doi: $10.1007 / \mathrm{s} 40333-013-0243-2$

jal.xjegi.com; www.springer.com/40333

\title{
Aeolian transport over a developing transverse dune
}

\author{
ZhiBao DONG*, Ping LV, ZhengCai ZHANG, JunFeng LU \\ Key Laboratory of Desert and Desertification, Cold and Arid Regions Environmental and Engineering Research Institute, Chinese \\ Academy of Sciences, Lanzhou 730000, China
}

\begin{abstract}
The spatial and temporal changes in aeolian transport over a dune are fundamental factors that control the morphology of the dune. In the present study, we obtained direct field observations of aeolian transport over a developing transverse dune at the Shapotou Aeolian Experiment Site in the southeastern part of China's Tengger Desert. The transport rate versus wind speed relationship is complicated over a developing dune compared with the relationships over flat surfaces and over dunes that are in equilibrium with the wind. We obtained trend lines for transport rate over the transverse dune versus distance. The transport rate generally increased from the toe to the crest above the stoss slope, but the difference in transport rate between the crest and the toe was smaller than those that have been proposed for taller dunes. The crest/toe ratio for transport rates therefore seems to depend greatly on dune height. Flux density profiles for different points above the dune at different wind speeds were well described by the exponential decay law, as has been proposed for saltation flux density profiles. Coefficients in the flux density profile function can be defined in terms of the transport rate and wind speed. However, the dependence of relative decay rate with height and average saltation height on wind speed was weaker than that observed in a wind tunnel and above a flat surface. The preliminary results obtained in this study require more evidence from field observations to fully describe aeolian transport above developing dunes.
\end{abstract}

Keywords: aeolian transport; aeolian geomorphology; dune dynamics

Citation: ZhiBao DONG, Ping LV, ZhengCai ZHANG, JunFeng LU. 2014. Aeolian transport over a developing transverse dune. Journal of Arid Land, 6(3): 243-254. doi: 10.1007/s40333-013-0243-2

Dunes are the most impressive and the most unquestionably aeolian of all aeolian landforms (Livingstone and Warren, 1996). Studies of dunes have typically focused on three main aspects: their morphology, sediments, and transport processes. Investigations of dune dynamics and transport processes, which the morphology and sediments are determined by, provide the key to understanding dune morphology and dune sediments. The goal of dune dynamics and process studies is to better understand the temporal and spatial changes in sediment transport because the initiation, development, and maintenance of dune morphology are controlled by temporal and spatial changes in sediment transport rates (Lancaster, 1995).

Extensive studies of dune dynamics and processes have been conducted by field observations (Burkin- shaw and Rust, 1993; Arens et al., 1995; Lancaster et al., 1996; McKenna Neuman et al., 2000; Nordstrom et al., 2007; Wren and Kuhnle, 2008; Baddock et al., 2011), wind tunnel simulations (Butterfield, 1998; Walker and Nickling, 2003; Dong et al., 2007), and numerical modeling (van Boxel et al., 1999; van Dijk et al., 1999; Momiji, 2000; Parsons et al., 2004; Delgado-Fernandez, 2011). Attention has recently shifted towards modeling approaches (Livingstone, 2007), taking advantage of recent advances in computer technology. However, great uncertainties remain. It is clear that the models will continue to require accurate field observations to validate and parameterize, and the improved models that result from these studies will help us understand dune dynamics and processes. Studies of dune geomorphology for the past several

*Corresponding author: ZhiBao DONG (E-mail: zbdong@1zb.ac.cn) Received 2013-04-17; revised 2013-06-17; accepted 2013-07-21

(C) Xinjiang Institute of Ecology and Geography, Chinese Academy of Sciences, Science Press and Springer-Verlag Berlin Heidelberg 2014 
decades have suggested that high-quality empirical data about sediment transport over dunes will let us more fully understand how dunes develop.

One bottleneck in the study of dune dynamics and processes has been a lack of knowledge about sediment transport over dunes. Most efforts since the 1970s have been devoted to measuring the airflow over dunes, and to indirectly estimating the potential transport rate in terms of dune dynamic processes by linking flow fields, sediment fluxes, and dune morphology (Burkinshaw and Rust, 1993; Arens et al., 1995; Frank and Kocurek, 1996; Livingstone, 2007). However, problems associated with the relationship between transport rate and airflow measurement over dunes have been increasingly recognized (Lancaster, 1994; Frank and Kocurek, 1996; Lancaster et al., 1996; Wiggs et al., 1996; Butterfield, 1998; Buffin-Bélanger et al., 2000; McKenna Neuman et al., 2000; Baas and Sherman, 2005; Walker, 2005). The problems are exacerbated by the secondary flow regime, inadequate measurement of near-surface shear stresses, and an incomplete understanding of the potential role of air turbulence (Livingstone, 2007) and of the relaxation process that occurs toward the saturation of sediment flux (Narteau et al., 2009). Therefore, despite recent advances in modeling of these processes, direct measurements of aeolian transport over dunes still appears to be necessary to understand the development of dunes.

Few field observations have measured aeolian transport over dunes (Wiggs, 1993; Lancaster, 1994; Sauermann et al., 2003; Hugenholtz et al., 2009). Preliminary knowledge suggests that sediment flux over barchan dunes increases from the toe to the crest (Wiggs, 1993; Lancaster et al., 1996; Sauermann et al., 2003). However, Lancaster et al. (1996) noted that the flux versus distance relationship over a 5-m-tall barchan dune varied among datasets. Sediment flux tends to increase exponentially with increasing distance up the dune at low wind speeds, whereas the increases become approximately linear at higher wind speeds (Lancaster, 1996). Field measurements by Sauermann et al. (2003) over a 34-m-tall barchan dune showed that the sediment flux increased almost linearly with increasing downwind distance and dune height. Fun- damental stages shared by all dunes include their initiation, development, and the maintenance of equilibrium morphology. Spatial changes in sediment transport affect these three stages differently because their morphological significance differs.

Barchan dunes and transverse dunes are the simplest dune types whose morphology is clearly related to the wind regime and have therefore been the most actively studied dune types. They both have slip faces that face roughly in the same direction and are characterized by net sand transport that is normal to their crests. Their morphology is controlled to a great extent by sediment transport over the stoss slope (Livingstone and Warren, 1996), where most field observations of dune dynamics and processes have been conducted. However, our knowledge of sediment transport even over these simple dune types remains inadequate, and knowledge of more complex dunes is more limited.

To support field observations, the Shapotou Aeolian Experiment Site was established in 2005 in the southeastern part of China's Tengger Desert by the Key Laboratory of Desert and Desertification, Chinese Academy of Sciences. Studies of dune dynamics and processes are among the primary goals of this station. In the present study, we obtained field observations of aeolian transport over a developing transverse dune. By using segmented sand samplers, we were able to analyze both transport rates and flux-density profiles.

\section{Field observations}

\subsection{Observation site and the developing dune}

The Shapotou Aeolian Experiment Site $\left(37^{\circ} 32^{\prime} \mathrm{N}\right.$, $105^{\circ} 02^{\prime} \mathrm{E}$ ) is located in the southeastern part of China's Tengger Desert. This area is a typical shifting dune field that is free of vegetation and dominated by dune networks (Fig. 1) that are composed of primary and subsidiary ridges. The primary ridges are transverse dunes aligned in a NE-SW direction, 4 to $20 \mathrm{~m}$ tall, and spaced at 30 to $170 \mathrm{~m}$. The subsidiary ridges are transverse dunes aligned in a NW-SE direction, 1 to $6 \mathrm{~m}$ tall, and spaced at 20 to $70 \mathrm{~m}$ (Hasi et al., 1999). Average annual precipitation is about $180 \mathrm{~mm}$, most of which falls in the summer and autumn (Fig. 2). 
Figure 3 shows the wind regime of the site, characterized using the drift potential parameter defined by Fryberger (1979).

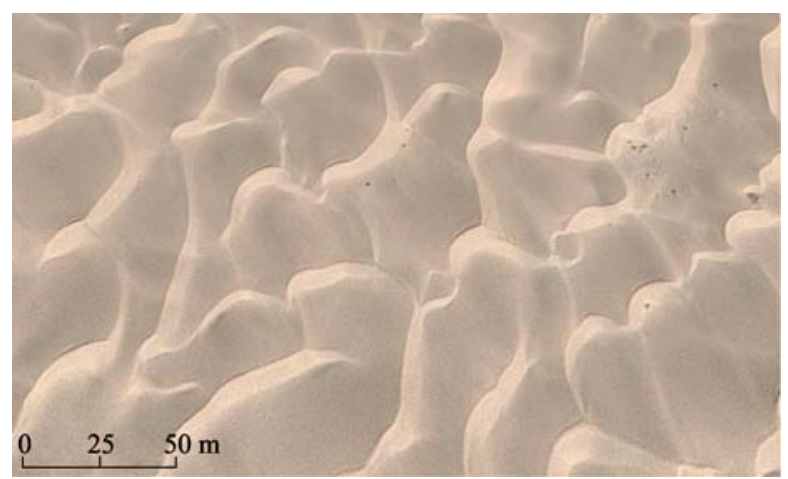

Fig. 1 Typical dune networks near the Shapotou Aeolian Experiment Site

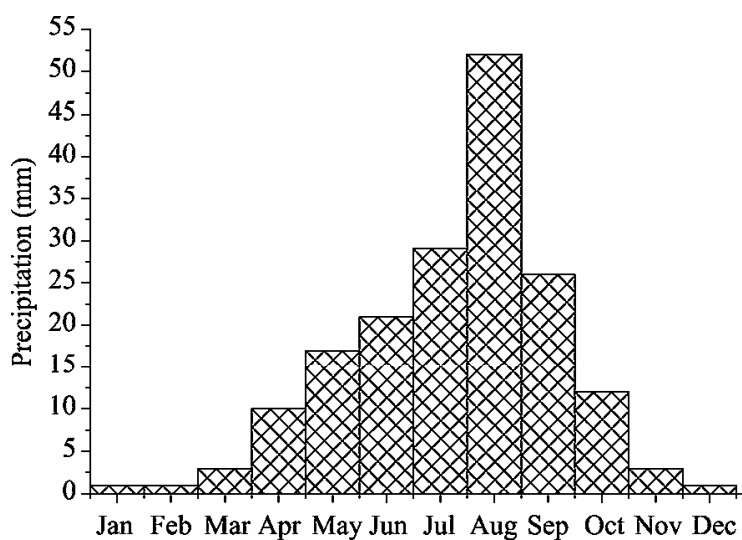

Fig. 2 Variation of monthly precipitation in the observation area

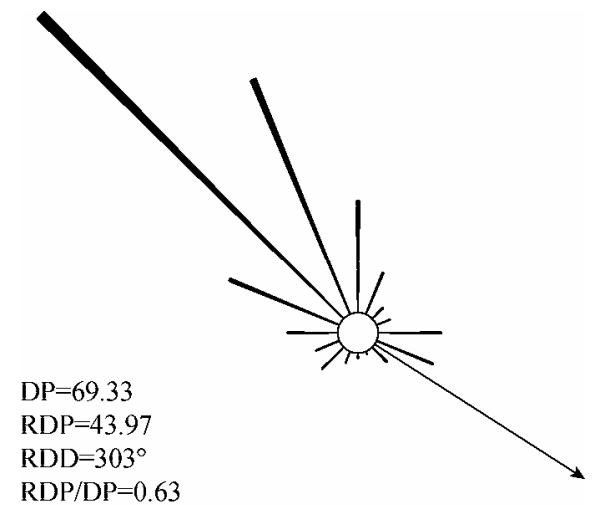

Fig. 3 Characterization of the wind regime in the study area using drift potential. DP, drift potential; RDP, resultant drift potential; RDD, resultant drift direction.

The dune observed in this study was a transverse dune aligned in a NE-SW direction, and developed within a $600 \mathrm{~m} \times 800 \mathrm{~m}$ experimental plot that was flattened in 2005 to allow new dunes to develop under natural conditions (Fig. 4). Hasi et al. (1999) suggested that the primary ridges of these dune networks formed under the influence of a dominant northwestern wind, and that the subsidiary ridges formed under the influence of a subdominant northeastern wind. The transverse dune that we observed will become a primary ridge, but it is currently in the early stage of its development. Its height has only reached $2.5 \mathrm{~m}$, which is much lower than the general height of the mature primary ridges. With $90 \%$ of the particles ranging between 0.125 and $0.250 \mathrm{~mm}$ in diameter, the dunes at the study site are composed of well-sorted fine sands, with a mean grain diameter (d) of $0.19 \mathrm{~mm}\left(\mathrm{M}_{\mathrm{z}}=2.42\right.$, which is a $\varphi$ value defined as $\left.-\log _{2} \mathrm{~d}\right)$, a standard deviation of $\sigma=0.41$, a skewness of $S_{k}=0.05$, and a kurtosis of $\mathrm{K}_{\mathrm{G}}=1.02$ (Fig. 5). The threshold wind velocity required for entrainment of the dune sediments is about $5 \mathrm{~m} / \mathrm{s}$.

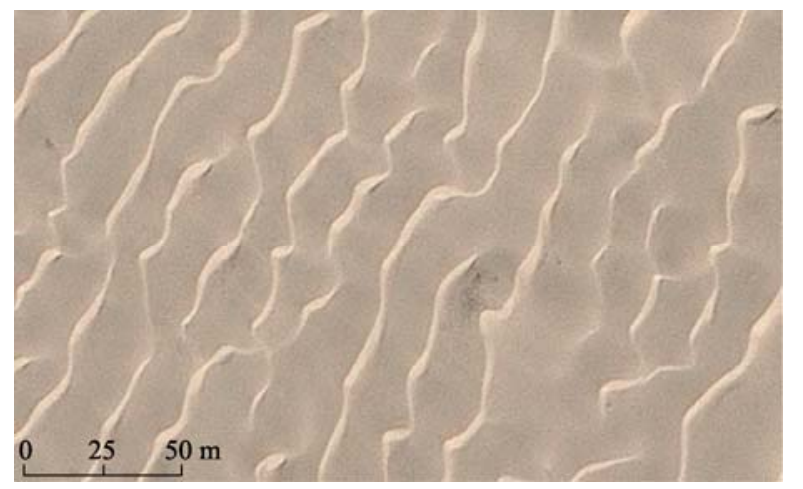

Fig. 4 Typical transverse dunes that developed around the dune observed in the present study

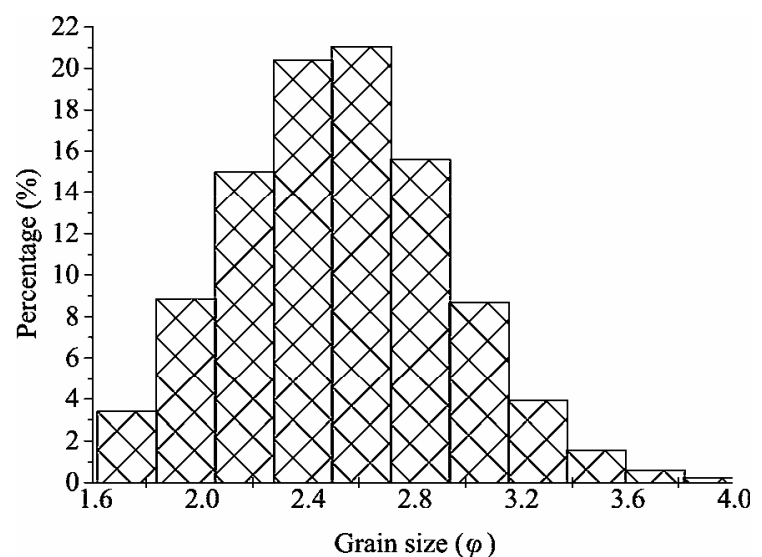

Fig. 5 Grain size distribution of the sediments in the dune networks in the study area 


\subsection{Observation methods}

In general, three distinct zones can be identified on the windward (stoss) slopes of fully developed dunes: the toe, the main slope, and the crest (Burkinshaw and Rust, 1993). We established four observation points on the transverse dune: the toe, mid-stoss, crest, and leeward foot of the dune (Fig. 6). The first three positions were chosen to let us describe aeolian transport over the three distinct zones on the stoss slope, even though it was not a fully developed dune. Another observation point was added at the foot of the leeward slope to provide a comparison. We observed aeolian transport over the transverse dune between March and May 2011, when aeolian transport events occurred frequently. Sediment transport was measured using vertical segmented sediment samplers (LDDSEG samplers) designed by the Key Laboratory of Desert and Desertification, Chinese Academy of Sciences (Dong et al., 2011). The samplers are $1 \mathrm{~m}$ tall, and are divided into 50 openings (each $20 \mathrm{~mm} \times 20 \mathrm{~mm}$ ) to collect the horizontally transported wind-eroded sediments at 50 heights at 20 -mm intervals. Each opening is connected to a sediment chamber that is inclined downward at an angle of $30^{\circ}$ with respect to the horizontal, and the chamber is removed after each observation period to weigh the collected sediments. Weight measurements were obtained using an electronic balance with $0.001-\mathrm{g}$ precision. The sampler design was evaluated in a wind tunnel before using it at the study site. Sampling efficiency for dune sands from this area ranged from $72 \%$ to $87 \%$. An overall sampling efficiency of $80 \%$ was adopted in the present study to correct the measured transport data. Simultaneous sediment transport observations were conducted at the four observation points using one LDDSEG sampler per point.
Wind data were acquired from a meteorological tower at the center of the study site at eight heights (1, $2,4,8,16,24,32$, and $48 \mathrm{~m}$ above the surface) using FC-1 wind sensors connected to a datalogger produced by the Changchun Meteorological Instrument Research Institute, China. The data acquisition system was set to record wind velocity at 1-min intervals. The mean wind velocity at $16 \mathrm{~m}$ for each observation period (a total of 18 aeolian transport events) was used to analyze its relationship with the flux density profiles and the transport rate. The prevailing wind was from the northwest during the observation period.

\section{Results and discussion}

A total of 18 aeolian transport events were observed. The duration of these events varied greatly, depending on the strength of the wind. The observation and analysis results are summarized in Table 1 .

\subsection{Transport rate}

The aeolian transport rate is defined as the mass of particles transported through a unit width perpendicular to the wind direction within a unit time $(\mathrm{kg} /(\mathrm{m} \cdot \mathrm{h}))$, and is obtained by summing up the sediment flux at all heights in the sampler. Figure 7 shows the transport rate for the four points as a function of wind speed. The relationship between transport rate and mean velocity during the observation period showed a wide scatter. This suggests that the transport rate versus distance relationship over the developing transverse dune varied among observation periods, as Lancaster et al. (1996) reported. However, in a previous study, we found that the aeolian transport rate in a flat shifting dune field increased linearly with the cube of the mean wind velocity during observations over a flat shifting dune field. It is possible that the relationship between transport rate and mean wind speed over

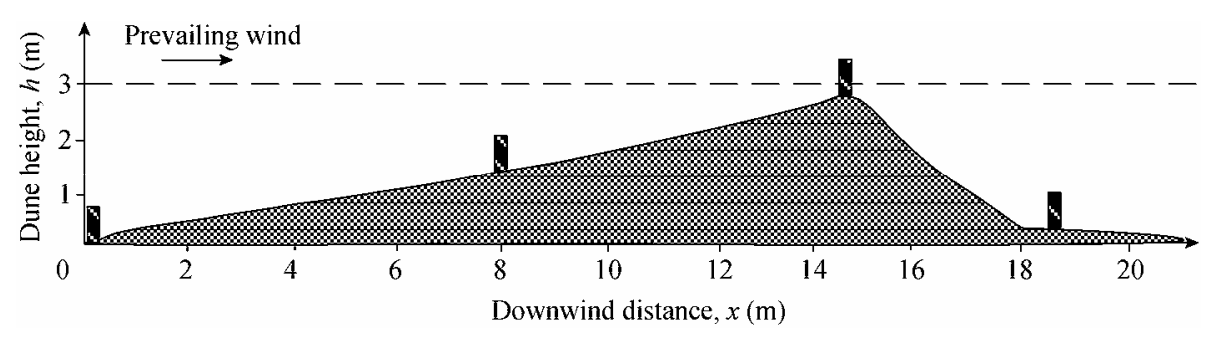

Fig. 6 Arrangement of the observation points on the developing transverse dune 
Table 1 Observed results of transport rate and results of the regression analyses for the flux density profiles at different points over the transverse dune

\begin{tabular}{|c|c|c|c|c|c|c|}
\hline Position on dune & $V(\mathrm{~m} / \mathrm{s})$ & $Q(\mathrm{~kg} /(\mathrm{m} \cdot \mathrm{h}))$ & $\bar{a}$ & $\bar{b}$ & $z_{\mathrm{a}}$ & $R^{2}$ \\
\hline \multirow[t]{18}{*}{ Toe } & 6.91 & 8.00 & 249.34 & 0.033 & 0.033 & 0.995 \\
\hline & 7.02 & 4.99 & 108.64 & 0.043 & 0.043 & 0.991 \\
\hline & 7.11 & 34.34 & 806.59 & 0.044 & 0.044 & 0.985 \\
\hline & 7.13 & 1.77 & 45.89 & 0.031 & 0.031 & 0.990 \\
\hline & 7.20 & 1.50 & 37.03 & 0.039 & 0.039 & 0.991 \\
\hline & 7.30 & 4.35 & 105.19 & 0.032 & 0.032 & 0.979 \\
\hline & 7.59 & 4.14 & 108.59 & 0.034 & 0.034 & 0.951 \\
\hline & 7.61 & 13.75 & 375.19 & 0.039 & 0.039 & 0.991 \\
\hline & 7.93 & 17.70 & 563.85 & 0.031 & 0.031 & 0.999 \\
\hline & 8.01 & 8.97 & 291.98 & 0.030 & 0.030 & 0.994 \\
\hline & 8.22 & 13.82 & 392.01 & 0.034 & 0.034 & 0.998 \\
\hline & 8.24 & 16.52 & 459.65 & 0.032 & 0.032 & 0.997 \\
\hline & 8.52 & 38.49 & $1,116.25$ & 0.036 & 0.036 & 0.992 \\
\hline & 8.71 & 4.87 & 115.87 & 0.036 & 0.036 & 0.992 \\
\hline & 9.07 & 14.42 & 338.82 & 0.037 & 0.037 & 0.996 \\
\hline & 9.29 & 22.68 & 462.75 & 0.046 & 0.046 & 0.998 \\
\hline & 9.38 & 14.43 & 297.53 & 0.039 & 0.039 & 0.988 \\
\hline & 10.19 & 13.39 & 240.82 & 0.037 & 0.037 & 0.905 \\
\hline \multirow[t]{18}{*}{ Mid-stoss } & 6.91 & 12.48 & 369.69 & 0.035 & 0.035 & 0.996 \\
\hline & 7.02 & 28.51 & 598.86 & 0.048 & 0.048 & 0.997 \\
\hline & 7.11 & 45.31 & $1,080.51$ & 0.045 & 0.045 & 0.977 \\
\hline & 7.13 & 7.44 & 244.42 & 0.030 & 0.030 & 0.999 \\
\hline & 7.20 & 12.38 & 326.51 & 0.040 & 0.040 & 0.985 \\
\hline & 7.30 & 28.19 & 742.69 & 0.040 & 0.040 & 0.988 \\
\hline & 7.59 & 7.06 & 296.96 & 0.024 & 0.024 & 0.999 \\
\hline & 7.61 & 17.44 & 527.32 & 0.034 & 0.034 & 0.998 \\
\hline & 7.93 & 16.59 & 614.94 & 0.027 & 0.027 & 0.999 \\
\hline & 8.01 & 15.18 & 470.68 & 0.032 & 0.032 & 0.998 \\
\hline & 8.22 & 11.88 & 392.29 & 0.030 & 0.030 & 0.998 \\
\hline & 8.24 & 37.62 & 796.35 & 0.049 & 0.049 & 0.988 \\
\hline & 8.52 & 19.73 & 644.40 & 0.031 & 0.031 & 0.996 \\
\hline & 8.71 & 29.31 & 609.47 & 0.050 & 0.050 & 0.986 \\
\hline & 9.07 & 28.41 & $1,023.52$ & 0.027 & 0.027 & 0.997 \\
\hline & 9.29 & 24.64 & 822.78 & 0.027 & 0.027 & 0.996 \\
\hline & 9.38 & 55.82 & $1,502.18$ & 0.036 & 0.036 & 0.999 \\
\hline & 10.19 & 54.44 & $1,076.58$ & 0.049 & 0.049 & 0.985 \\
\hline \multirow[t]{10}{*}{ Crest } & 6.91 & 6.76 & 232.46 & 0.030 & 0.030 & 0.996 \\
\hline & 7.02 & 22.36 & 515.96 & 0.045 & 0.045 & 0.990 \\
\hline & 7.11 & 21.51 & 585.13 & 0.037 & 0.037 & 0.996 \\
\hline & 7.13 & 35.01 & $1,106.18$ & 0.033 & 0.033 & 0.999 \\
\hline & 7.20 & 9.24 & 305.56 & 0.030 & 0.030 & 0.997 \\
\hline & 7.30 & 19.02 & 588.22 & 0.034 & 0.034 & 0.996 \\
\hline & 7.59 & 25.78 & 785.32 & 0.033 & 0.033 & 0.997 \\
\hline & 7.61 & 18.05 & 562.16 & 0.033 & 0.033 & 0.989 \\
\hline & 7.93 & 15.80 & 482.57 & 0.032 & 0.032 & 0.997 \\
\hline & 8.01 & 24.75 & 806.97 & 0.032 & 0.032 & 0.997 \\
\hline
\end{tabular}




\begin{tabular}{|c|c|c|c|c|c|c|}
\hline Position on dune & $V(\mathrm{~m} / \mathrm{s})$ & $Q(\mathrm{~kg} /(\mathrm{m} \cdot \mathrm{h}))$ & $a$ & $b$ & $z_{\mathrm{a}}$ & $\overline{R^{2}}$ \\
\hline \multirow{26}{*}{ Leeward foot } & 8.22 & 14.15 & 397.10 & 0.036 & 0.036 & 1.00 \\
\hline & 8.24 & 48.28 & $1,208.38$ & 0.040 & 0.040 & 0.97 \\
\hline & 8.52 & 25.41 & 706.53 & 0.036 & 0.036 & 0.99 \\
\hline & 8.71 & 46.35 & 705.86 & 0.067 & 0.067 & 0.99 \\
\hline & 9.07 & 43.18 & 889.11 & 0.046 & 0.046 & 0.99 \\
\hline & 9.29 & 55.99 & $1,313.23$ & 0.043 & 0.043 & 0.99 \\
\hline & 9.38 & 51.26 & 719.59 & 0.067 & 0.067 & 0.99 \\
\hline & 10.19 & 94.27 & $1,205.04$ & 0.082 & 0.082 & 0.97 \\
\hline & 6.91 & 4.30 & 144.54 & 0.031 & 0.031 & 0.97 \\
\hline & 7.02 & 2.14 & 57.64 & 0.026 & 0.026 & 0.98 \\
\hline & 7.11 & 9.00 & 274.05 & 0.031 & 0.031 & 0.96 \\
\hline & 7.13 & 0.11 & 2.65 & 0.048 & 0.048 & 0.99 \\
\hline & 7.20 & 1.20 & 36.45 & 0.030 & 0.030 & 0.97 \\
\hline & 7.30 & 2.56 & 85.52 & 0.031 & 0.031 & 0.98 \\
\hline & 7.59 & 2.56 & 49.73 & 0.040 & 0.040 & 0.79 \\
\hline & 7.61 & 12.19 & 363.34 & 0.035 & 0.035 & 0.99 \\
\hline & 7.93 & 9.58 & 283.64 & 0.033 & 0.033 & 0.99 \\
\hline & 8.01 & 16.71 & 591.05 & 0.027 & 0.027 & 0.99 \\
\hline & 8.22 & 9.89 & 283.69 & 0.034 & 0.034 & 0.99 \\
\hline & 8.24 & 8.56 & 181.98 & 0.042 & 0.042 & 0.95 \\
\hline & 8.52 & 25.51 & 818.71 & 0.032 & 0.032 & 0.99 \\
\hline & 8.71 & 4.62 & 75.29 & 0.033 & 0.033 & 0.91 \\
\hline & 9.07 & 10.02 & 121.87 & 0.042 & 0.042 & 0.86 \\
\hline & 9.29 & 43.65 & $1,376.53$ & 0.031 & 0.031 & 0.97 \\
\hline & 9.38 & 13.18 & 114.13 & 0.059 & 0.059 & 0.76 \\
\hline & 10.19 & 9.57 & 171.40 & 0.038 & 0.038 & 0.96 \\
\hline
\end{tabular}

Note: Results are arranged in order of increasing wind speed. Values represent the regression parameters for the function $q(z)=a e^{-z / b}$, where $q(z)$ is flux density at height $z, z$ is the height above the surface, and $a$ and $b$ are regression parameters. $Q$ is the measured transport rate. $V$ represents the free-stream wind velocity at a height of $16 \mathrm{~m} . Z_{\mathrm{a}}$ is the average saltation height. $R^{2}$ is the correlation coefficient at $P<0.05$.

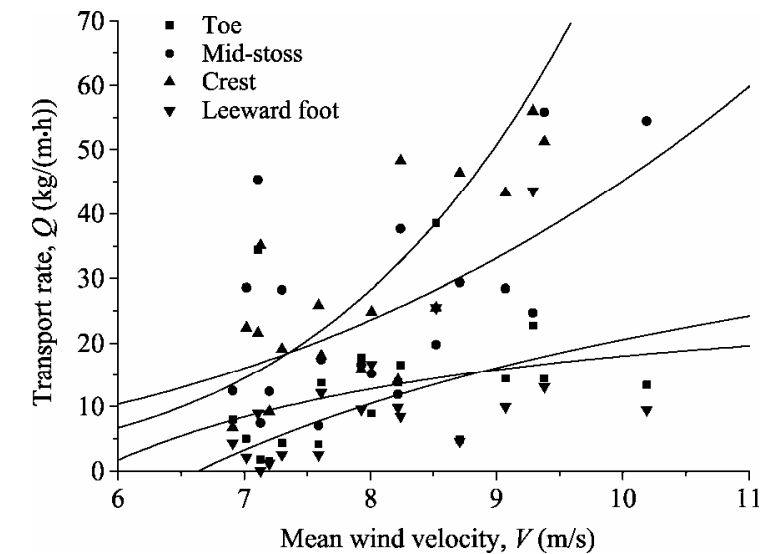

Fig. 7 Observed transport rates as a function of wind speed. Lines represent the regressions of transport rate versus wind speed ( $Q$ versus $V$ trend lines) at different points over the dune.

dunes is complicated by factors that have not yet been identified or that have been identified but not ade- quately described (e.g. variation in wind speed and turbulence). In this sense, the mean wind speed parameter may not adequately characterize the transport rate over dunes.

Narteau et al. (2009) suggested that it is extremely important to distinguish between steady-state or homogeneous conditions and transient conditions in studies that relate the sediment transport rate to wind parameters, including wind shear. Under steady-state conditions, the influence of the shear stress magnitude $\left(\tau_{\mathrm{s}}\right)$ on the sediment transport rate can be evaluated. The role of bed slope and cohesion on the threshold shear stress value for motion inception $\left(\tau_{\mathrm{c}}\right)$ can also be investigated. In all cases, the sediment transport rate converges toward an equilibrium value that can be described as "saturated". The transport laws then pre- 
cisely specify the expression of the function $Q_{\mathrm{sat}}\left(\tau_{\mathrm{s}}, \tau_{\mathrm{c}}\right)$. Under nonhomogeneous or non-steady-state conditions, such as those that occur over a developing dune, the actual transport rate $(Q)$ does not immediately adjust to changes in the local value of the shear stress or wind velocity. The transport needs some time to reach its equilibrium value $\left(Q_{\text {sat }}\right)$. This phenomenon can be described as a "relaxation" process that occurs before saturation of the sediment transport rate. It is also important to distinguish between developing dunes that have variable morphology and dunes that are in equilibrium with the local wind field. For a developing dune, whose morphology is not yet in equilibrium with the wind, its morphology must frequently adjust to changes in wind properties. Especially when the wind is very variable, the relaxation process by which the transport rate responds to wind changes may lead to a poorer correlation between the transport rate and the mean wind speed.

The variation in the transport rate as a function of distance varied from run to run, but our results nonetheless suggest a general trend. In general, the transport rates were similar at the toe and the leeward foot; they increased from toe to crest, where the greatest transport rate occurred (Fig. 8). Though the change in transport rate with increasing wind speed showed considerable variation at all four observation points, trend lines could be found. Figure 8 shows the variation in transport rate as a function of distance at different wind velocities derived from the trend lines for transport rate as a function of wind speed (the $Q-V$ trend lines) at the four observation positions. The increase over the stoss slope is obvious, and is qualitatively in agreement with previous results (Wiggs, 1993; Lancaster et al., 1996; Sauermann et al., 2003). However, the shapes of the lines representing the increase with distance differ among wind speeds. Lancaster et al. (1996) found that the shape of transport rate versus distance curve varied in response to variations in the wind speed conditions. Sauermann et al. (2003) suggested that for a dune that migrates downwind without changing its shape, a straight line is expected for this relationship. However, for a dune that is not in equilibrium with the wind, any functional dependence can be obtained.

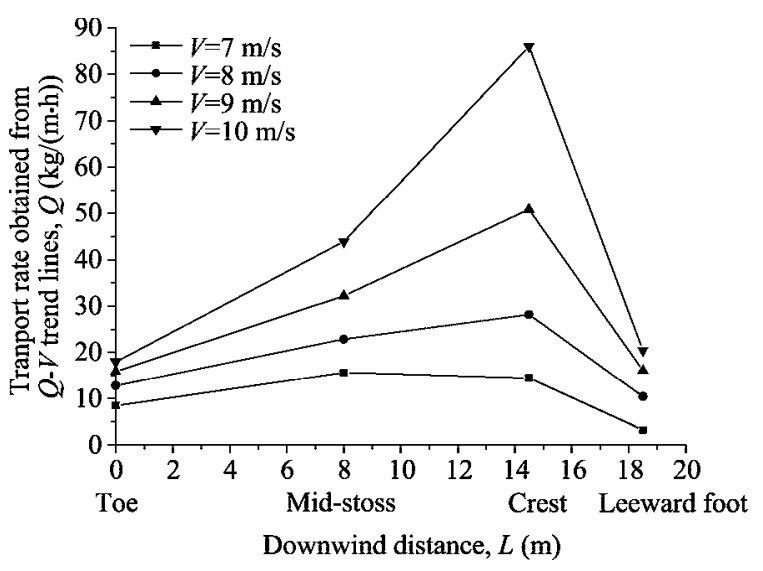

Fig. 8 Transport rates as a function of distance at different wind speeds obtained from the $Q-V$ trend lines

The difference in transport rate between the crest and toe positions (Fig. 9) was smaller than the ratios reported by Lancaster et al. (1996) and Sauermann et al. (2003). Lancaster et al. (1996) found that the crest/toe mean transport ratio over a 5-m-tall barchan dune ranged between 11 and 42, decreasing linearly with increasing wind shear velocity measured at the dune toe. Sauermann et al. (2003) found that the ratio was about 65 over a 34-m-tall barchan dune. But the crest/toe mean transport ratios over the transverse dune in the present study ranged between 1.7 and 4.8. The large differences among these studies are largely due to differences in dune height. Comparison of the results of Lancaster et al. (1996), Sauermann et al. (2003), and the present study suggests that the taller the dune, the greater the difference between the crest and toe transport rates. An outstanding difference between Lancaster et al.'s (1996) results and the

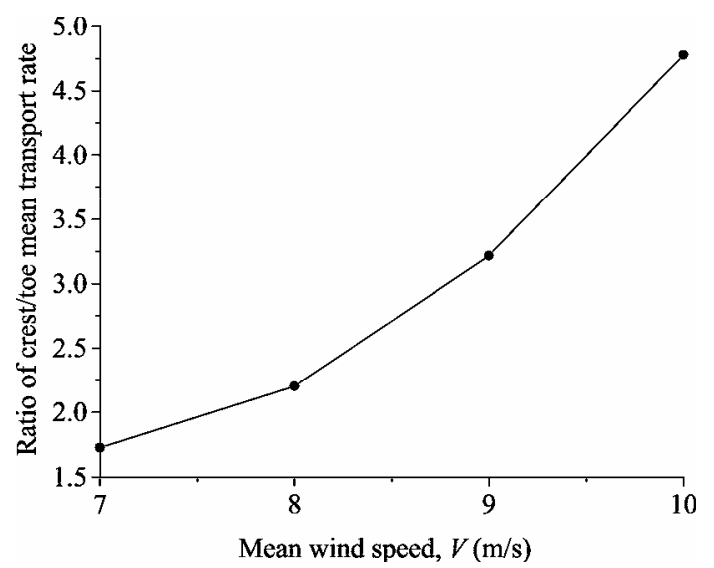

Fig. 9 Variation in the ratio of crest/toe transport rate as a function of wind speed 

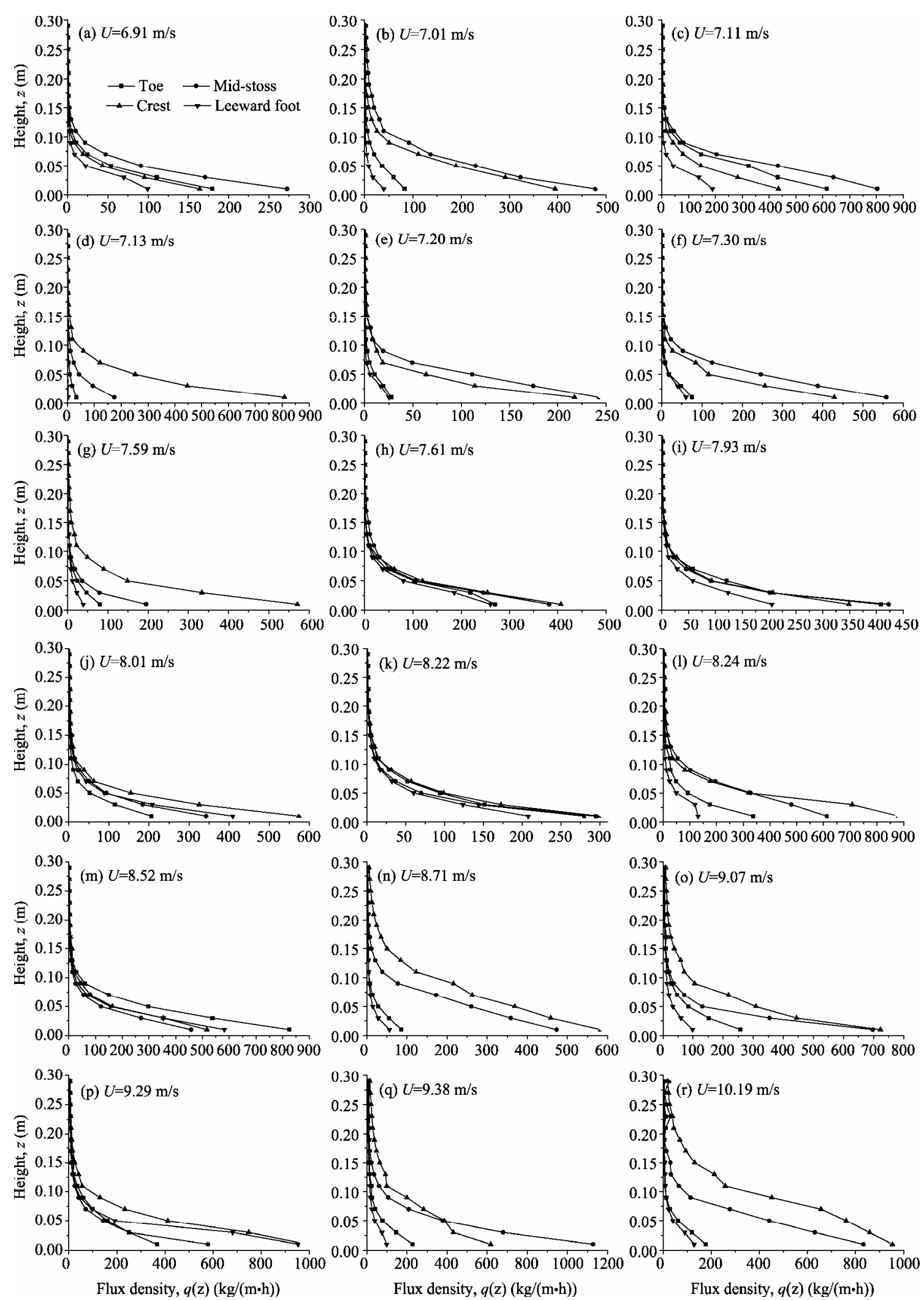

Fig. 10 Calculated flux density profiles based on observed sediments collected to a height of $1 \mathrm{~m}$ at the four points on the transverse dune (their locations are shown in Fig. 6). Numbers beside wind speeds refer to the 18 aeolian transport events summarized in Table 1. The graphs use different scales for flux density. 
present results is the change in the crest/toe transport ratio with wind speed. Their results showed that this ratio decreased linearly with increasing wind speed, but the present result showed the opposite trend, namely that the ratio increased almost linearly with increasing wind speed (Fig. 9). These discrepancies suggest that more field observations of sediment transport should be conducted over dunes at different wind speeds and with a range of dune heights.

\subsection{Flux density profiles}

Sediment flux density, $q(z)$, is generally expressed as the mass of sediment passing through a unit area perpendicular to the transport direction within a unit time. To establish the sediment flux density profiles, we converted the observed sediment masses at each observation height into units of $\mathrm{kg} /(\mathrm{m} \cdot \mathrm{h})$. Figure 10 shows the variation in observed sediment flux density as a function of height (i.e. the geometric mean height at the center of each sample position) for each of the four observation positions as a function of mean wind speed.

Sediment flux over the developing transverse dune mainly occurred at heights below $0.3 \mathrm{~m}$ above the surface. Regression analyses showed that for all observation points and all wind speeds, the flux density decays exponentially with height:

$$
q(\mathrm{z})=a \mathrm{e}^{-\mathrm{z} / b} .
$$

Where $q(z)$ is the flux density at height $z$, and $a$ and $b$ are regression coefficients. Table 1 indicates that in more than $80 \%$ of the cases, the correlation coefficient $\left(R^{2}\right)$ for this relationship was greater than or equal to 0.98 .

An ideal flux density profile function should also be a good predictor of the transport rate. Integration of the flux density profile function as a function of height yields the calculated transport rate $\left(Q_{c}\right)$ :

$$
Q_{c}=\int_{0}^{1} a e^{-z / b} d z
$$

To confirm the goodness of fit of Eq. 1, we compared the transport rate calculated using Eq. 2 with the observed transport rate obtained by summing up the observed mass flux at all heights (Fig. 11). The fit was strong and statistically significant $\left(R^{2}=0.99, p<0.05\right)$. Therefore, Eq. 1 provides an adequate description of the aeolian flux density profiles at the four positions on the dune. This may be because the particle-size distribution at the study site (Fig. 5) was mostly within the range for particles that are transported by saltation (Pye and Tsoar, 1990). It is now widely accepted that the mass flux density of suspended sediments decays with increasing height following a power function (Zingg, 1953; Liu, 1960; Nickling, 1978; Takeuchi, 1980; Fryrear, 1987; Ni et al., 2002), whereas that of saltating sediments decays with increasing height following an exponential decay function such as Eq. 1 (Kawamura, 1951; Horikawa and Shen, 1960; Nalpanis, 1985; Nalpanis et al., 1993; Dong et al., 2003). Our results confirm this belief.

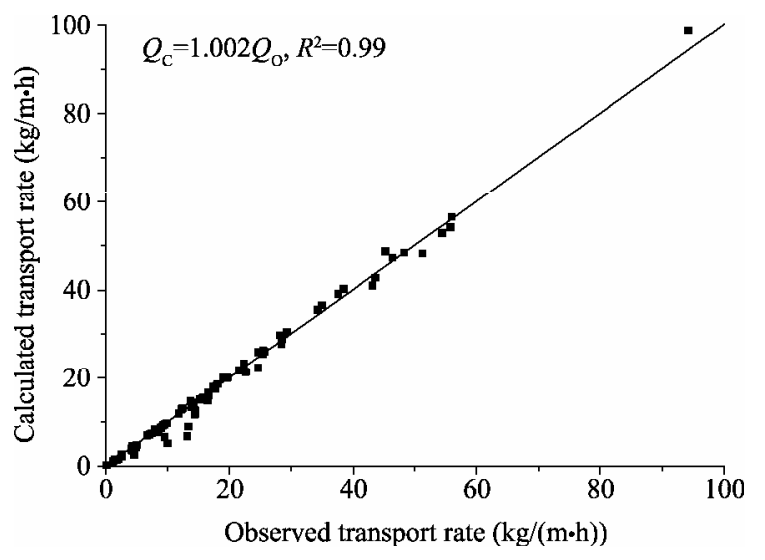

Fig. 11 Comparison of the observed transport rate $\left(Q_{\circ}\right)$ and the transport rate $\left(Q_{c}\right)$ calculated from the flux density using Eq. 2

The regression coefficients in Eq. 1 can be defined as a function of wind speed and aeolian transport rate. As in the case of the flux density profiles over flat surface, the coefficient $a$ is a function of the transport rate (Fig. 12), and increases linearly with an increase in the square root of the transport rate.

We can derive the following from Eq. 1:

$$
\frac{d \ln q(z)}{d z}=-\frac{1}{b} \text {. }
$$

Thus, the regression coefficient $b$ in Eq. 1 characterizes the relative decay rate of flux density with increasing height. The greater the $b$ value, the more gently the flux density decays with height. Figure 13 shows that the relative decay rate depends on the wind speed, but is independent of the position on the dune. Because coefficient $b$ increases with increasing wind speed, the decay rate of flux density decreases with increasing wind speed. However, the dependence of the relative decay rate on wind speed over a dune is 
weaker than that over a flat surface (Dong et al., 2003), indicating that the transport rate versus wind speed relationship is complicated over a developing dune.

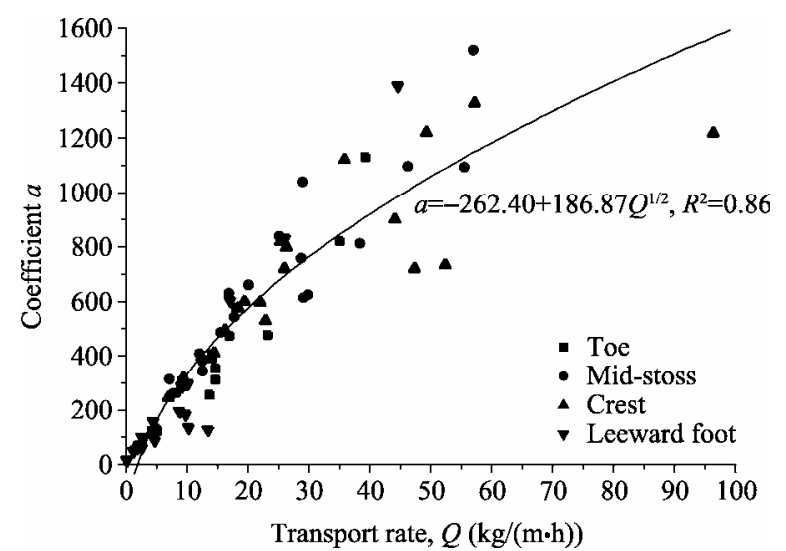

Fig. 12 The relationship between the value of coefficient $a$ in Eq. 1 and the observed transport rate

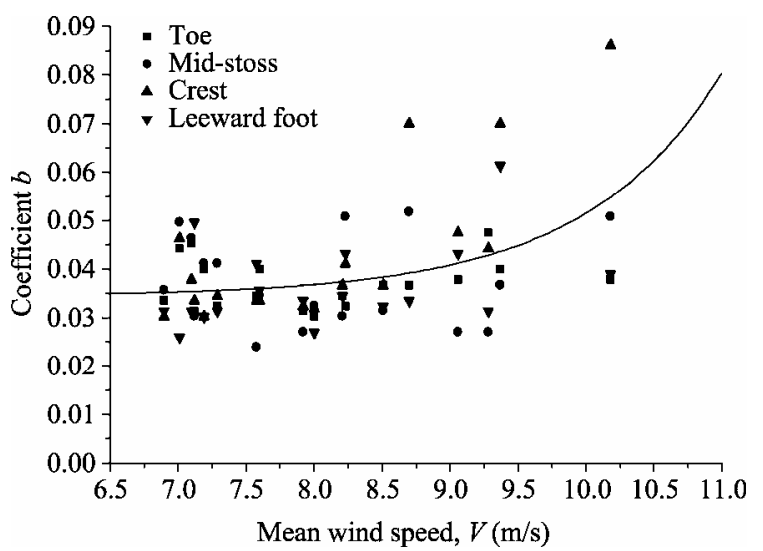

Fig. 13 The relationship between the value of coefficient $b$ in Eq. 1 and the observed wind speed

The relationship between relative decay rate of the saltation flux and the wind speed can be explained in terms of saltation intensity, which is characterized by the average saltation height:

$$
z_{a}=\frac{\int_{0}^{\infty} q(z) z d z}{\int_{0}^{\infty} q(z) d z} .
$$

Where $z_{\mathrm{a}}(\mathrm{m})$ is the average saltation height. In the present study, we calculated the average saltation height $\left(z_{\mathrm{a}}\right)$ using the following equation:

$$
z_{\mathrm{a}}=\frac{\int_{0}^{1} q(z) z d z}{\int_{0}^{1} q(z) d z}=\frac{a b^{2}\left[1-\left(1 / b^{+1) e^{-1 / b}}\right]\right.}{a b\left(1-e^{-1 / b}\right)} .
$$

Table 1 indicates that the average saltation height equaled the corresponding value of $b$. This is because the value of $b$ in the present study was so small that the value of $e^{-1 / b}$ in Eq. 5 was almost negligible. In that case, Eq. 5 can be simplified as $Z_{\mathrm{a}} \cong b$.

It is worth noting that $b$ will become significantly greater when saltation increases in intensity, and that $z_{\mathrm{a}}$ will then differ increasingly from the coefficient $b$. Our analysis suggests that the relative decay rate and the average saltation height are two aspects of the same physical phenomenon, and that a greater saltation height corresponds to a lower relative decay rate.

These results indicate that the flux density profiles for the four observation points are adequately described by the coefficients $a$ and $b$ in Eq. 1 .

\section{Conclusions}

Spatial and temporal changes in sediment transport over dunes is a fundamental factor that controls the morphology of dunes and their evolution. The transport rate versus distance relationship is different for dunes at different stages of development, such as initiation, development, and maintenance of equilibrium morphology. Based on our field observation data, we analyzed variations in sediment transport rate and flux density profiles over a developing transverse dune.

The relationship between transport rate and wind speed over the developing dune was complicated compared with that over a flat surface and that over dunes that are in equilibrium with their local wind environment, so the transport rate versus distance relationship varied among observation periods. The general trend for the relationship between transport rate and distance was that transport rate increased from the toe of towards the crest of the stoss slope. The difference in transport rate between the crest and the toe depends strongly on dune height, so the crest/toe ratio for transport rate over the $2.5-\mathrm{m}$-tall transverse dune in the present study was much lower than those calculated for taller dunes. Contrary to Lancaster et al.'s conclusion (based on field observations) that the crest/toe ratio for transport rate decreased with increasing wind velocity measured at the toe, we found that this ratio increased with increasing wind speed. 
The flux density profiles at the four positions on the dune closely followed the exponential decay law that has been proposed for saltation flux density profiles. The coefficients in the flux density profile function can be defined in terms of transport rate and wind speed. However, due to the complicated relationship between transport rate and wind speed, the dependence of the relative decay rate and average saltation height on wind speed was less significant than was suggested by previous studies based on wind tunnel tests and field observations.

The present study involved relatively few direct measurements of the aeolian transport rate over a developing dune. Thus, these preliminary results should be supported by additional field observations.

\section{Acknowledgments}

We gratefully acknowledge funding from the National Natural Science Foundation of China (41130533, 41171010).

\section{References}

Arens S M, van Kaam P, van Boxel J H. 1995. Airflow over foredunes and implications for sand transport. Earth Surface Processes and Landforms, 20: 315-332.

Baas A C W, Sherman D J. 2005. Formation and behavior of aeolian streamers. Journal of Geophysical Research: Earth Surface, 110: F03011, doi: 10.1029/2004JF000270.

Baddock M C, Wiggs G F S, Livingstone I. 2011. A field study of mean and turbulent flow characteristics upwind, over and downwind of barchan dunes. Earth Surface Processes and Landforms, 36: 1435-1448.

Buffin-Bélanger T, Roy A G, Kirkbride A D. 2000. On large-scale flow structures in a gravel-bed river. Geomorphology, 32: 417-435.

Burkinshaw I K, Rust I C. 1993. Aeolian dynamics on the windward slope of a reversing dune, Alexandria coastal dunefield, South Africa. Special Publication of the International Association of Sedimentologists, 16: 13-21.

Butterfield G R. 1998. Transitional behavior of saltation: wind tunnel observations of unsteady winds. Journal of Arid Environments, 39: 377-394.

Delgado-Fernandez I. 2011. Meso-scale modelling of aeolian sediment input to coastal dunes. Geomorphology, 130: 230-243.

Dong Z, Liu X, Wang H, et al. 2003. The flux profile of a blowing sand cloud: a wind tunnel investigation. Geomorphology, 49: 219-230.

Dong Z, Qian G, Luo W, et al. 2007. A wind tunnel simulation of the effects of stoss slope on the lee airflow pattern over a two-dimensional transverse dune. Journal of Geophysical Research-Earth Surface, 112: F03019, doi: 10.1029/ 2006JF000686.

Dong Z, Lu J, Man D, et al. 2011. Equations for the near-surface mass flux density profile of wind-blown sediments. Earth Surface Processes and Landforms, 36: 1292-1299.

Frank A, Kocurek G. 1996. Airflow up sand dunes: limitations of current understanding. Geomorphology, 17: 47-54.

Fryberger S G. 1979. Dune forms and wind regime. In: Mckee E D. A Study of Global Sand Seas. Washington: U.S. Government Printing Office, 137-160.

Fryrear D W. 1987. Aerosol measurements from 31 dust storms. In: Ariman T, Veziroglu T N. Particulate and Multiphase Flows: Contamination Analysis and Control. New York: Hemisphere Publishing Corp., 407-415.

Hasi E, Dong G, Wang G. 1999. Morphodynamic study of reticulate dunes at southeastern fringe of the Tengger Desert. Science in China: Series D, 42: 208-215.

Horikawa K, Shen H W. 1960. Sand movement by wind: on the characteristics of sand traps. Technical Memorandum. Washington, DC: Beach Erosion Board, U. S. Army Corps, 119.

Hugenholtz C H, Wolfe S A, Walker I J, et al. 2009. Spatial and temporal patterns of aeolian sediment transport on an inland parabolic dune, Bigstick Sand Hills, Saskatchewan, Canada. Geomorphology, 105: 158-170.

Lancaster N, Nickling W G, McKenna Neuman C, et al. 1996. Sediment flux and airflow on the stoss slope of a barchan dune. Geomorphology, 17: 55-62.

Liu C. 1960. Transfer of sand in the surface layer. Acta Meteorologica Sinica, 31: 75-83.

Livingstone I, Warren A. 1996. Aeolian Geomorphology: An Introduction. England: Addison Wesley Longman Limited, 211.

Livingstone I. 2007. Geomorphology of desert dunes: a review of recent progress. Earth-Science Reviews, 80: 239-257.

McKenna Neuman C, Lancaster N, Nickling W G. 2000. The effect of unsteady winds on sediment transport on the stoss slope of a transverse dune, Silver Peak, NV, USA. Sedimentology, 47: 211-226.

Momiji H, Carretero-González R, Bishop S R. 2000. Simulation of the effect of wind speedup in the formation of transverse dune fields. Earth Surface Processes and Landforms, 25: 905-918.

Nalpanis P. 1985. Saltating and suspended particles over flat and sloping surfaces: II. experiments and numerical simulations. In: Barndorff-Nielsen O E, Møller J T, Rasmussen K R, et al. Proceedings of International Workshop on the Physics of Blown Sand. Denmark: Aarhus University, 37-66.

Nalpanis P, Hunt J C R, Barrett C F. 1993. Saltating particles over flat beds. Journal of Fluid Mechanics, 251: 661-685.

Narteau C, Zhang D, Rozier O, et al. 2009. Setting the length and time scales of a cellular automaton dune model from the analysis of superimposed bed forms. Journal of Geophysical Research, 114: 
F03006, doi: 10.1029/2008JF001127.

Ni J R, Li Z S, Mendoza C. 2002. Vertical profiles of aeolian sand mass flux. Geomorphology, 49: 205-218.

Nickling W G. 1978. Eolian sediment transport during dust storms: Slims River Valley, Yukon Territory. Canadian Journal of Earth Science, 15: 1069-1084.

Nordstrom K F, Jackson N L, Hartman J M, et al. 2007. Aeolian sediment transport on a human-altered foredune. Earth Surface Processes and Landforms, 32: 102-115.

Parsons D R, Walker I J, Wiggs G F S. 2004. Numerical modelling of flow structures over idealized transverse aeolian dunes of varying geometry. Geomorphology, 59: 149-164.

Pye K, Tsoar H. 1990. Aeolian Sand and Sand Dunes. London: Unwin Hyman Ltd., 396.

Sauermann G, Andrade Jr J S, Maia L P, et al. 2003. Wind velocity and sand transport on a barchan dune. Geomorphology, 54: 245-255.

Takeuchi M. 1980. Vertical profile and horizontal increase of drift-snow transport. Journal of Glaciology, 26: 492-498.

van Boxel J H, Arens S M, van Dijk P M. 1999. Aeolian processes across transverse dunes. I: modelling the air flow. Earth Surface Processes and Landforms, 24: 255-270.

van Dijk P M, Arens S M, van Boxel J H. 1999. Aeolian processes across transverse dunes. II: modelling the sediment transport and profile development. Earth Surface Processes and Landforms, 24: 319-333.

Walker I J, Nickling W G. 2003. Simulation and measurement of surface shear stress over isolated and closely spaced transverse dunes in a wind tunnel. Earth Surface Processes and Landforms, 28: 1111-1124.

Walker I J. 2005. Physical and logistical considerations of using ultrasonic anemometrys in aeolian sediment transport research. Geomorphology, 68: 57-76.

Wiggs G F S. 1993. Desert dune dynamics and the evaluation of shear velocity: an integrated approach. In: Pye K. The Dynamics and Environmental Context of Aeolian Sedimentary System. Geological Society Special Publication, London: 72.

Wiggs G F S, Livingstone I, Warren A. 1996. The role of streamline curvature in sand dune dynamics: evidence from field and wind tunnel measurements. Geomorphology, 17: 29-46.

Wren D G, Kuhnle R A. 2008. Measurements of coupled fluid and sediment motion over mobile sand dunes in a laboratory flume. International Journal of Sediment Research, 23: 329-337.

Zingg A W. 1953. Some characteristics of aeolian sand movement by saltation process. Édition du Center National de la Recherche Scientifique, 7: 197-208. 